\title{
TITLE:
}

\section{Asymmetric aldol reaction via memory of chirality.}

\section{AUTHOR(S):}

Watanabe, Hidetoshi; Yoshimura, Tomoyuki; Kawakami, Shimpei; Sasamori, Takahiro; Tokitoh, Norihiro; Kawabata, Takeo

\section{CITATION:}

Watanabe, Hidetoshi ...[et al]. Asymmetric aldol reaction via memory of chirality.. Chemical communications 2012, 48(43): 5346-5348

\section{ISSUE DATE:}

2012-04-03

URL:

http://hdl.handle.net/2433/173623

\section{RIGHT:}

(c) The Royal Society of Chemistry 2012; This is not the published version. Please cite only the published version.; この論文は出版社版で ありません。引用の際には出版社版をご確認ご利用ください。 


\title{
Asymmetric aldol reaction via memory of chirality $\dagger$
}

\author{
Toshihide Watanabe, Tomoyuki Yoshimura, Shimpei Kawakami, Takahiro Sasamori, Norihiro Tokitoh \\ and Takeo Kawabata*
}

Received (in $X X X, X X X)$ Xth $X X X X X X X X X 20 X X$, Accepted Xth $X X X X X X X X X 20 X X$

${ }_{5}$ DOI: 10.1039/b000000x

Asymmetric aldol reactions of $\alpha$-amino acid derivatives via memory of chirality were developed. Chiral oxazolidones with contiguous tetra- and trisubstituted chiral centers were obtained in $\mathbf{7 8 - 9 4 \%}$ ee by the asymmetric aldol reaction 10 followed by intramolecular acylation.

We have studied asymmetric induction via memory of chirality. ${ }^{1,2}$ This strategy enables a direct construction of $\alpha$-amino acid derivatives with chiral tetrasubstituted carbon from readily available $\alpha$-amino acids without the aid of external chiral sources 15 such as chiral catalysts or chiral auxiliaries. We have reported several asymmetric intramolecular transformations via memory of chirality such as alkylation, ${ }^{3}$ conjugate addition, ${ }^{4}$ and Dieckmann condensation. ${ }^{5}$ On the other hand, intermolecular transformation via memory of chirality has been limited only to 20 simple alkylation and allylation. ${ }^{6} \quad$ The relative difficulties in developing intermolecular asymmetric transformation by this strategy originates in the nature of intermediary enolates. Since the intermediary chiral enolates are prone to undergo timedependent racemization, relatively slow intermolecular processes

25 appear to be more difficult than the corresponding intramolecular ones. Here, we report the first example of asymmetric intermolecular aldol reactions between $\alpha$-amino acid derivatives and aromatic aldehydes via memory of chirality through careful investigation of the balance between the racemization behaviour 30 of intermediary chiral enolates and their reactivity toward aldehydes. $^{7}$

We have reported that $\alpha$-methylation of an amino acid derivative via memory of chirality (Scheme 1). ${ }^{6 a}$ The asymmetric transformation was proposed to proceed via axially chiral enolate $35 \mathbf{A}$. The half-life of racemization of $\mathbf{A}$ was measured to be $22 \mathrm{~h}$ at the reaction temperature $\left(-78{ }^{\circ} \mathrm{C}\right)$, which corresponds to the racemization barrier of the chiral enolate to be $16.0 \mathrm{kcal} / \mathrm{mol}$. Since the reaction rate of enolate $\mathbf{A}\left(k_{\text {reaction (A) }}\right)$ with electrophiles is same as that of enolate ent-A $\left(k_{\text {reaction (ent-A) }}\right)$, the ratio between ${ }_{40} \mathbf{A}$ and ent-A directly correlates with the ee of the product. The ratio between $k_{\text {reaction (A) }}$ and $k_{\text {racemization }}$ critically affects overall

Institute for Chemical Research, Kyoto University, Uji, Kyoto 611-0011, Japan. Fax: 8177438 3197; Tel: 8177438 3190; E-mail:

45 kawabata@scl.kyoto-u.ac.jp

$\dagger$ Electronic Supplementary Information (ESI) available: Experimental procedures, caharacterization data, copies of ${ }^{1} \mathrm{H}$ NMR and ${ }^{13} \mathrm{C}$ NMR. CCDC-867310 for 10. See DOI: 10.1039/b000000x/ efficiency of the asymmetric transformation. Choice of a solvent 50 mixture (toluene:THF=4:1) is the key for the high yield and asymmetric induction. Use of the major volume of toluene is effective for slowing the racemization of enolate $\mathbf{A},{ }^{8}$ probably due to the formation of higher-order aggregates of the enolate. On the other hand, use of the minor volume of THF seems to be ${ }_{55}$ effective for increasing the reactivity of the enolate to promote smooth alkylation. ${ }^{9}$ Based on the backgrounds on the nature of the intermediary chiral enolates, we envisaged to develop asymmetric aldol reactions through careful consideration of the balance between $k_{\text {reaction }}$ of the aldol reaction and $k_{\text {racemization }}$ of the 60 chiral enolate intermediate.

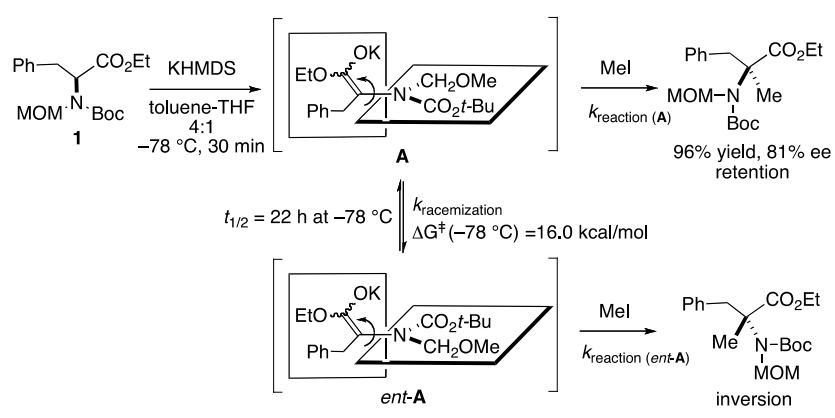

Scheme 1 A reaction path of asymmetric methylation via axially chiral enolate $\mathbf{A}$.

65

We chose N-tert-butoxycarbonyl (Boc)- $N$ methoxymethyl(MOM)-amino acid derivative $\mathbf{1}$ as the substrate for the development of asymmetric aldol reactions, because the racemization behaviour of chiral enolate $\mathbf{A}$ generated from $\mathbf{1}$ has 70 been well studied. ${ }^{6 a, 8}$ Asymmetric aldol reaction of $\mathbf{1}$ was first examined according to the protocol for asymmetric $\alpha$ methylation shown in Scheme 1. Treatment of $\mathbf{1}$ with 1.1 equivalents of potassium hexamethyldisilazide (KHMDS) in toluene-THF (4:1) for $30 \mathrm{~min}$ to generate axially chiral enolate $75 \mathbf{A},{ }^{6 a}$ followed by addition of 3.0 equivalents of benzaldehyde (procedure I in Table 1) gave oxazolidone derivative 2 in $85 \%$ yield and only $32 \%$ ee after intramolecular acylation of the resulting potassium aldolate with the Boc moiety (entry 1). In order to avoid partial racemization of the chiral enolate during the 80 aldol reaction and to gain insights into the asymmetric induction at the early stage of the aldol reaction, another reaction procedure was employed. A solution of $\mathbf{1}$ was added to a pre-cooled solution 
of benzaldehyde (3.0 equiv.) and KHMDS (1.1 equiv.) (procedure II) in toluene-THF $(4: 1)$ at $-78{ }^{\circ} \mathrm{C}$, and the resulting solution was stirred for only $10 \mathrm{~min}$ to give 2 in $2 \%$ yield and $99 \%$ ee (entry 2). Treatment of $\mathbf{1}$ under the identical conditions to 5 those in entry 2 except for the temperature $\left(-30{ }^{\circ} \mathrm{C}\right)$ gave 2 in a slightly increased yield (7\%) and a slightly decreased ee $(96 \%)$ (entry 3$)$. The reaction with the prolonged reaction time $(4 \mathrm{~h})$ at the same temperature $\left(-30{ }^{\circ} \mathrm{C}\right)$ gave 2 in $96 \%$ yield in a decreased ee $(71 \%$ ee) (entry 4$)$. Comparison of the results between entries 103 and 4 indicates partial racemization of the intermediary chiral enolate during its reaction with benzaldehyde. According to our observation on racemization behaviour of the enolate, ${ }^{8,9}$ pure toluene was employed as a solvent in order to minimize racemization of the chiral enolate. Product $\mathbf{2}$ was obtained in a 15 increased ee ( $80 \%$ ee) by the reaction of $\mathbf{1}$ in toluene even after the longer reaction time $(6 \mathrm{~h})$ than that employed for the corresponding reaction in toluene-THF (4:1) (71\% ee after $4 \mathrm{~h}$ ) (entries 4 vs. 5). In order to further increase both the yield and the ee of the reaction, another procedure was examined. Three 20 equivalents of KHMDS were added to a pre-cooled solution of benzaldehyde (5.0 equiv.) and $\mathbf{1}$ (procedure III) in toluene at -30 ${ }^{\circ} \mathrm{C}$, and the resulting solution was stirred for $6 \mathrm{~h}$ to give $\mathbf{2}$ in $86 \%$ yield and $83 \%$ ee (entry 6). While decrease in the reaction temperature to $-50{ }^{\circ} \mathrm{C}$ increased the ee of the aldol reaction to ${ }_{25} 87 \%$ ee, that diminished the yield to $65 \%$ (entries 6 vs. 7). Ethereal solvents were employed in combination with toluene in order to improve the yield by increasing the reactivity of the enolate (entries 8-10 vs. 7). While the addition of either THF, $i$ $\mathrm{Pr}_{2} \mathrm{O}$, or $t$-BuOMe is effective in increasing the yield of the

Table 1 Optimization of asymmetric aldiol reactions via memory of chirality.

\begin{tabular}{|c|c|c|c|c|c|c|}
\hline \multicolumn{3}{|c|}{$\overbrace{\mathrm{MOM}_{1}^{-\mathrm{N}}}^{\mathrm{Ph}}+\mathrm{Ph}-\mathrm{CHO}+\mathrm{KHMDS} \longrightarrow$} & \multicolumn{2}{|c|}{ 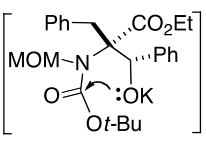 } & \multicolumn{2}{|c|}{$\underset{\mathrm{O}}{\mathrm{MOM}-\mathrm{N}_{2}} \stackrel{\mathrm{N}}{\mathrm{CO}_{2} \mathrm{E}}$} \\
\hline entry & procedure $^{a}$ & solvent & temp $\left({ }^{\circ} \mathrm{C}\right)$ & time & yield $(\%)^{b, c}$ & $\mathrm{ee}^{d}(\%)$ \\
\hline 1 & I & toluene: $\mathrm{THF}=4: 1$ & -78 & $2.5 \mathrm{~h}$ & 85 & 32 \\
\hline 2 & II & toluene: $\mathrm{THF}=4: 1$ & -78 & $10 \mathrm{~min}$ & 2 & 99 \\
\hline 3 & II & toluene: $\mathrm{THF}=4: 1$ & -30 & $10 \mathrm{~min}$ & 7 & 96 \\
\hline 4 & II & toluene: $\mathrm{THF}=4: 1$ & -30 & $4 \mathrm{~h}$ & 96 & 71 \\
\hline 5 & II & toluene & -30 & $6 \mathrm{~h}$ & 57 & 80 \\
\hline 6 & III & toluene & -30 & $6 \mathrm{~h}$ & 86 & 83 \\
\hline 7 & III & toluene & -50 & $10 \mathrm{~h}$ & 65 & 87 \\
\hline 8 & III & toluene:THF=2:1 & -50 & $12 \mathrm{~h}$ & 86 & 78 \\
\hline 9 & III & toluene: $i-\mathrm{Pr}_{2} \mathrm{O}=2: 1$ & -50 & $12 \mathrm{~h}$ & 95 & 84 \\
\hline 10 & III & toluene: $t$-BuOMe $=2: 1$ & -50 & $12 \mathrm{~h}$ & quant & 81 \\
\hline 11 & III & toluene: $i-\mathrm{Pr}_{2} \mathrm{O}=2: 1$ & -60 & $12 \mathrm{~h}$ & 70 & 86 \\
\hline 12 & III & toluene: $t$-BuOMe $=2: 1$ & -60 & $12 \mathrm{~h}$ & 69 & 92 \\
\hline $13^{e}$ & III & toluene: $t$-BuOMe $=2: 1$ & -50 & $12 \mathrm{~h}$ & $31^{f}$ & 89 \\
\hline $14^{g}$ & III & toluene: $t$-BuOMe $=2: 1$ & -50 & $12 \mathrm{~h}$ & quant $^{h}$ & 82 \\
\hline
\end{tabular}

${ }^{a} \mathrm{I}: 1$ was tretated with KHMDS (1.1 equiv.) for $30 \mathrm{~min}$, then with benzaldehyde (3.0 equiv.) for $2 \mathrm{~h}$. II: A solution of $\mathbf{1}$ was added to a solution of benzaldehyde (3.0 equiv.) and KHMDS (1.1 equiv.). III: KHMDS (3.0 equiv.) was added to a solution of benzaldehyde (5.0 equiv.) and $1 .{ }^{b} \mathrm{~A}$ single diastereomer was obtained in each run. ${ }^{c}$ The relative configuration was determined by NOE studies (see ESI) as well as an X-ray analysis of the derivative of $\mathbf{2}$ (see text). ${ }^{d}(4 S, 5 S)$-Isomer was obtained in each run. For determination of the absolute configuration, see text. ${ }^{e}$ The corresponding tert-butyl ester was employed as a substrate. ${ }^{f}$ The yield of the corresponding tert-butyl ester. $g$ The corresponding benzyl ester was employed as a substrate. ${ }^{h}$ The yield of the correspondin benzyl ester. reaction (86\% quant), that slightly decreased the enantioselectivity of the aldol process $(78 \sim 84 \%$ ee). The 35 corresponding reactions at $-60^{\circ} \mathrm{C}$ increased the ee to $86 \sim 92 \%$ ee (entries 11 and 12). Based on these results, we chose the conditions employed in entries 10 and 12, procedure III in toluene- $t$-BuOMe $(2: 1)$, as the optimum ones. The corresponding tert-butyl and benzyl esters of $\mathbf{1}$ were treated under the reaction 40 conditions employed for entry 10 gave the corresponding tertbutyl and benzyl esters of $\mathbf{2}$ in $89 \%$ ee ( $31 \%$ yield) and $82 \%$ ee (quant), respectively (entries 13 and 14).

The optimized conditions were applied to asymmetric aldol reactions of $\mathbf{1}$ with various aromatic aldehydes (Table 2). A 45 mixture of $\mathbf{1}$ and an aldehyde in toluene- $t$-BuOMe (2:1) was treated with KHMDS at $-60{ }^{\circ} \mathrm{C}$ or $-50{ }^{\circ} \mathrm{C}$ to give a chiral oxazolidone with contiguous tetra- and trisubstituted chiral centers in diastereomerically pure form through the asymmetric aldol reaction followed by intramolecular acylation of the 50 resulting potassium aldolate. para-Substituted benzaldehydes gave oxazolidones 3-6 by the reactions with 1 in $64-95 \%$ yield and $78-88 \%$ ee (entries 2-5). ortho-Methoxybenzaldehyde underwent the aldol-acylation reaction to give oxazolidone 7 in $67 \%$ yield and $89 \%$ ee (entry 6). Reaction of 1 with 255 naphthaldehyde gave oxazolidone $\mathbf{8}$ in high enantioselectivity (89\% ee) and a low yield (44\%) (entry 7). Although a single diastereomer was obtained in each run after purification by column chromatography, the involvement of the minor diastereomer in the crude mixture can not be excluded, especially 60 when the yield was low. The attempted reactions of $\mathbf{1}$ with aliphatic aldehydes did not afford the significant amounts of aldolates or the corresponding oxazolidones.

Table 2 Asymmtric aldiol reactions of $\mathbf{1}$ with aromatic aldehydes. ${ }^{a}$

\begin{tabular}{|c|c|c|c|c|c|c|}
\hline Entry & $\mathrm{Ar}$ & temp $\left({ }^{\circ} \mathrm{C}\right)$ & time (h) & product $^{b, c}$ & yield (\%) & ee $(\%)$ \\
\hline 1 & & -60 & 6 & $2^{d}$ & 69 & 92 \\
\hline 2 & & -60 & 12 & $3^{e}$ & 67 & 88 \\
\hline 3 & & -60 & 6 & $4^{e}$ & 66 & 88 \\
\hline 4 & & -50 & 6 & $\mathbf{5}^{e}$ & 64 & 78 \\
\hline 5 & & -50 & 12 & $6^{e}$ & 95 & 80 \\
\hline 6 & & -50 & 12 & $7^{e}$ & 67 & 89 \\
\hline 7 & & -60 & 6 & $8^{e}$ & 44 & 89 \\
\hline
\end{tabular}

${ }^{a}$ KHMDS (3.0 equiv.) was added to a solution of an aldehyde (5.0 equiv.) and 1. ${ }^{b}$ A single diastereomer was obtained in each run. ${ }^{c}$ Relative configuration of 2-6 and 8 was determined by NOE studies, see ESI. Relative configuration of 7 was tentatively assigned by analogy. ${ }^{d}(4 S, 5 S) .{ }^{e}$ The absolute configuration was tentatively assigned by analogy to 2 .

65

The absolute configuration of $\mathbf{2}$ was determined by an X-ray analysis of its derivative $\mathbf{1 0}$ (Figure 1). Hydrolysis of $\mathbf{2}$ (85\% ee) obtained by the reactions in Table 1 followed by condensation of 
the resulting acid with $(S)$-1-(1-naphthyl)ethylamine gave 9 in $86 \%$ yield as a diastereomerically pure form after column chromatography. Treatment of $\mathbf{9}$ with trifluoroacetic acid gave 10 in $85 \%$ yield via Pictet-Spengler cyclization, in which the 5 MOM group serves as a formaldehyde equivalent. ${ }^{10}$ An X-ray structure of a single crystal of $\mathbf{1 0}$ is shown in Figure 1. This indicates that asymmetric aldol reaction of $\mathbf{1}$ took place in inversion of configuration at the newly generated tetrasubstituted carbon center. Asymmetric aldol reactions of tyrosine derivative $10 \mathbf{1 1}$ and leucine derivative $\mathbf{1 3}$ with benzaldehyde took place by the treatment according to the protocol in Table 2 gave oxazolidones $\mathbf{1 2}$ and $\mathbf{1 4}$ in $85 \%$ ee (95\% yield) and $94 \%$ ee ( $83 \%$ yield), respectively.

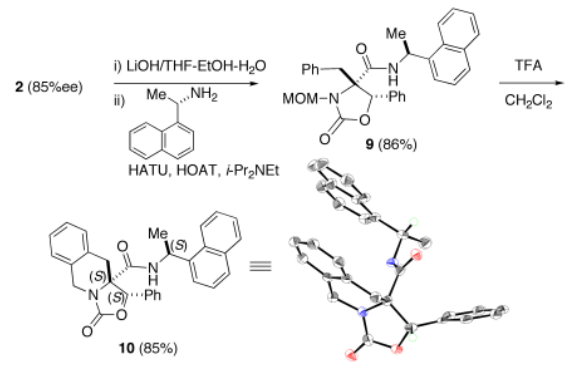

Figure 1 Transformation of $\mathbf{2}$ into $\mathbf{1 0}$ and an X-ray structure of $\mathbf{1 0}$. 15

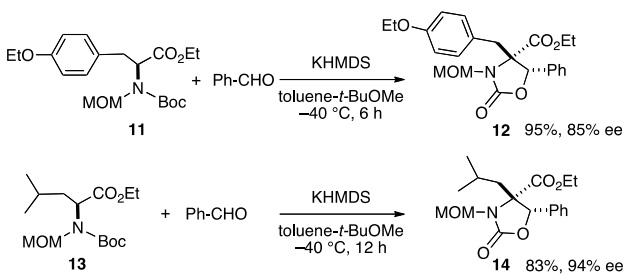

Scheme 2 Asymmetric aldol-acylation reactions of $\mathbf{1 1}$ and $\mathbf{1 3}$.

The following phenomena appear to be intriguing from mechanistic viewpoints and enolate chemistry. (1) While 20 methylation of $\mathbf{1}$ proceeds in retention of configuration, its aldol reaction took place in inversion of configuration. These reactions seem to proceed via a common chiral enolate intermediate (at least for the reactions of entry 1 in Table 1 and Scheme 1). Thus, the reacting enantioface of the axially chiral enolate is reverse to 25 each other depending on the electrophile (alkyl halide or aldehyde). (2) While the enolate generated from $\mathbf{1}$ by the procedure I (entry 1 in Table 1 and Scheme 1 ) has been known to be a 2:1 $\mathrm{Z} / \mathrm{E}$ mixture, ${ }^{\text {aa }}$ its aldol reaction with benzaldehyde gave a diastereomerically pure product in $85 \%$ yield. Some of other 30 related aldol reactions also gave diastereomerically pure products in good yields. We are not ready to propose the rationale for these phenomena, yet. Mechanistic investigations are currently underway in our laboratory.

In conclusion, we have developed an intermolecular 35 asymmetric aldol reaction of $\alpha$-amino acid derivatives via memory of chirality for the first time. ${ }^{7}$ Although asymmetric aldol reactions have extensively developed, ${ }^{11,12}$ the present method has unique characteristics in which asymmetric induction is controlled solely by the enolate chirality in the absence of 40 chiral catalysts or chiral auxiliaries. Chiral oxazolidone derivatives with contiguous tetra- and trisubstituted chiral centers can be obtained from readily available $\alpha$-amino acids by the present method in a highly diastereoselective and enantioselective manner. Chiral oxazolidones have been known to be useful chiral 45 auxiliaries, ${ }^{11}$ and recently disclosed to be a novel class of antibiotics. ${ }^{13}$ Oxazolidones obtained by the present method are structural equivalents to $\beta$-hydroxy- $\alpha$-amino acids with a tetrasubstituted carbon center, ${ }^{14}$ which are the frequently observed structural subunits in biologically active natural 50 products. $^{15}$

\section{Notes and references}

1 For reviews on asymmetric synthesis via memory of chirality: (a) $\mathrm{T}$. Kawabata, K. Fuji, Topics in Stereochemistry 2003, 23, 175. (b) H. Zhao, D. C. Hsu, P. R. Carlier, Synthesis 2005, 1. (c) T. Kawabata,

55 ACS Symposium Series 1009. "Asymmetric Synthesis and Application of $\alpha$-Amino Acids", 2009. pp.31-56.

2 For recent examples of asymmetric synthesis based on memory of chirality: (a) P. R. Carlier, H. Zhao, S. L. MacQuarrie-Hunter, J. C. DeGuzman, D. C. Hsu, J. Am. Chem. Soc. 2006, 128, 15215. (b) L.

60 Klolaczkowski, D. M. Barnes, Org. Lett. 2007, 9, 3029. (c) M. Branca, D. Gori, R. Guillot, V. Alezra, C. Koulovsky, J. Am. Chem. Soc. 2008, 130, 5864. (d) G. N. Wanyoike, Y. Matsumura, M. Kuriyama, O. Onomura, Heterocycles, 2010, 80, 1177. (e) M. Sasaki, T. Takegawa, H. Ikemoto, M, Kawahara, K. Yamaguchi, K. Takeda, Chem. Commun. 2012, 48, 2897.

3 T. Kawabata, S. Kawakami, S. Majumdar, J. Am. Chem. Soc. 2003 , 125, 13012. (b) T. Kawabata, S. Matsuda, S. Kawakami, D. Monguchi, K. Moriyama, J. Am. Chem. Soc. 2006, 128, 15394. (c) T. Kawabata, K. Moriyama, S. Kawakami, K. Tsubaki, J. Am. Chem. Soc. 2008, 130, 4153.

4 T. Kawabata, S. Majumdar, K. Tsubaki, D. Monguchi, Org. Biomol. Chem. 2005, 3, 1609.

5 T. Watanabe, T. Kawabata, Heterocycles 2008, 76, 1593.

6 (a) T. Kawabata, H. Suzuki, N. Nagae, K, Fuji, Angew. Chem. Int. Ed. 2000, 39, 2155. (b) T. Kawabata, J. Chen, H. Suzuki, Y. Nagae, T. Kinoshita, S. Chancharunee, K. Fuji, Org. Lett. 2000, 2, 3883. (c) T. Kawabata, S. Kawakami, S. Shimada, K. Fuji, Tetrahedon 2003, 59, 965.

7 An intramolecular aldol reaction with memory of chirality has 80 previously been reported, see: A. G. Brewster, C. F. Frampton, J. Jayatissa, M. B. Mitchell. R. J. Stoodley, S. Vohra, Chem. Commun., 1998, 299

8 The half-life of racemization of enolate $\mathbf{A}$ in pure THF at $-78^{\circ} \mathrm{C}$ was determined to be $0.5 \mathrm{~h}$, which is $\sim 1 / 40$ of that in toluene-THF $(4: 1)$.

${ }_{85} 9$ While the reaction in pure THF gave the $\alpha$-methylated product in 93\% yield and $35 \%$ ee (reference $6 \mathrm{c}$ ), the corresponding reaction in pure toluene gave the $\alpha$-methylated product in $47 \%$ yield and $75 \%$ ee This could be ascribed to be higher reactivity of the enolate in THF and registance of the enolate against racemization in toluene.

9010 T. Kawabata, O. Ozürk, H. Suzuki, K. Fuji, Synthesis, 2003, 505.

11 For reviews on chiral auxiliary-based asymmetric synthesis including asymmetric aldol reactions: (a) D. A. Evans, Aldrichimica Acta 1982, 15, 23. (b) D. A. Evans, G. Helmchen, M. Ruping, J. Wolfgang, Asymmetric Synthesis, 2007, 3.

9512 For pioneering examples for catalytic asymmetric aldol reactions: (a) S. Kobayashi, Y. Fujisawa, T. Mukaiyama, Chem. Lett. 1990, 1455. (b) H. Sasai, T. Suzuki, S. Arai, T. Arai, M. Shibasaki, J. Am. Chem. Soc. 1992, 114, 4418. (c) B. List, R. A. Lerner, C. F. Barbas, III, J. Am, Chem. Soc. 2000, 122, 2395.

10013 For selected reviews: (a) M. Barbachyn, C. W. Ford, Angew. Chem. Int. Ed. 2003, 42, 2010. (b) T. A. Mukhtar, G. D. Wright, Chem. Rev. $2005, \mathbf{1 0 5}, 529$.

14 For selected recent examples of catalytic asymmeric sythesis of $\beta$ hyrdoxy- $\alpha$-amino acid derivatives with a tetrasubstituted carbon 105 center: (a) M. Terada, H. Tanaka, K. Sorimachi, J. Am. Chem. Soc. 2009, 131, 3430. (b) T. Yoshino, H. Morimoto, G. Lu, S. Matsunaga, M. Shibasaki, J. Am. Chem. Soc. 2009, 131, 3430.

15 For a review, see: S. H. Kang, S. Y. Kang, H-S. Lee, A. J. Buglass, Chem. Rev. 2005, 105, 17082. 